Journal of Archaeological Science: Reports 20 (2018) 476-482 DOI:

10.1016/j.jasrep.2018.06.001

\title{
Integration of neutron-based elemental analysis and imaging methods and applications to cultural heritage research
}

\author{
László Szentmiklósi, Boglárka Maróti, Zoltán Kis, Zsolt Kasztovszky \\ Nuclear Analysis and Radiography Department, Centre for Energy Research, Hungarian \\ Academy of Sciences, 29-33 Konkoly-Thege Miklós street, 1121 Budapest, Hungary.
}

\begin{abstract}
The present paper describes the merits of the combined neutron-based elemental analysis and neutron imaging techniques, called prompt-gamma activation imaging - neutron tomography (PGAI-NT), and illustrates its application to cultural heritage science with relevant case studies. The approach is proven to be best applicable to samples with corroded/layered/gilded/painted/coated structures where the surface weighted response would bias the analysis results obtained with simpler, more widespread, but less representative techniques (such as X-ray fluorescence spectroscopy or laser-ablation ICPMS), as well as to answer questions related to the inner composition of a sealed object.
\end{abstract}

\section{Keywords}

Non-destructive elemental analysis, prompt-gamma activation imaging, neutron imaging, PGAI-NT, NIPS-NORMA station, handheld XRF

\section{Highlights}

- Integration of neutron imaging and elemental analysis functionalities into a single instrument, NIPS-NORMA at the Budapest Neutron Centre (BNC)

- Synergetic effects of the multi-technique approach at the data interpretation stage

- Non-destructive analysis of archaeological iron, bronze and pottery was completed 
Journal of Archaeological Science: Reports 20 (2018) 476-482 DOI:

10.1016/j.jasrep.2018.06.001

\section{Introduction}

\subsection{Evolution of neutron-analytical techniques towards use by the cultural heritage community}

One of the priorities at the Budapest Neutron Center (BNC) is to promote the collaboration between the cultural heritage $(\mathrm{CH})$ experts and neutron scientists. This has been facilitated by several EU-funded transnational access (TNA) programs (NMI3, NMI3-II, CHARISMA, IPERION CH) as well as method-development projects (e.g. EU FP6 NEST ANCIENT CHARM) (Belgya et al., 2008b; Giorini et al., 2009; Schulze et al., 2010).

The EU FP7 CHARISMA and EU H2020 IPERION CH projects offer integrated access to several instruments located on a single campus (e.g. at BNC: imaging at RAD ( $\mathrm{Z}$ Kis et al., 2015) or NORMA (Z. Kis et al., 2015), elemental analysis at PGAA (Szentmiklósi et al., 2010) or NIPS (Szentmiklósi et al., 2013), and neutron diffraction at ToF-ND (Káli et al., 2007)), or even at different radiation sources, such as neutrons, ion beams and synchrotron radiation. An innovative question-answering approach, a user "welcome desk", and the active support by the neutron experts throughout the entire workflow made the cultural heritage users able to answer many questions by use of neutron methods.

There has been a second aspect of evolution at the facility level, also driven by the needs of the user community. Neutron techniques for elemental analysis and diffraction were originally developed to deal with point like, or at least regularly shaped, pure and homogeneous samples (Mackey et al., 1996), (Kudejova et al., 2015). In particular, promptgamma activation analysis (PGAA) (Molnár, 2004) has always been an excellent technique for the fully non-destructive characterization of valuable (and preferably homogeneous) artifacts, such as stone tools, glassware, pottery, bronze alloys, and coins. This research has resulted in over one hundred publications in this field (Szentmiklósi et al., 2016). A significant proportion of the cultural heritage samples are, however, neither regular-shaped nor homogeneous, e.g. painted ceramics, precious stone inlays of metals, gilding, surfaces with corrosion or patina. To make PGAA capable of analyzing such objects, an extension of the base technique was needed, where instead of bulk average composition a local 
Journal of Archaeological Science: Reports 20 (2018) 476-482 DOI:

10.1016/j.jasrep.2018.06.001

elemental analysis is done and the composition determined is linked to a definite part of the object.

Another prominent technique, neutron imaging is perfect to reveal the internal structure of the heterogeneous objects (Lehmann, 2017; Lehmann et al., 2017; Schillinger et al., 2018; Szilágyi et al., 2016), with a spatial resolution far better than what neutron-based elemental analysis can ever offer. It cannot, however, provide unambiguous evidence about the materials used, since by coincidence more than one material can have the same macroscopic attenuation property. An object's internal structure and its production technology can sometimes be understood only if multi-modality imaging (Thermal neutron vs. cold neutron, Neutron vs. X-ray imaging) is applied.

\subsection{Best practices, synergies and complementarities}

Experience has showed that a multi-technique approach (Edge et al., 2015; Kasztovszky et al., 2016; Kiss et al., 2015), even if they carried out separately, offers synergies when interpreting the results. E.g., for alloys with more than two components, like ancient bronze artefacts, Vergard's law for binary alloys (Vergard, 1921) is not applicable. It can be extended to ternary alloys if the object is classified to a proper subcategory, such as leadbronze, brass, tin-bronze, where different calibration curves apply (Sidot et al., 2005). With the information on the bulk average composition from a PGAA experiment, this can be done successfully (Gliozzo et al., 2017). Conversely, oxygen is hard to quantify in corroded iron by PGAA due to the low analytical sensitivity for oxygen, whereas the diffraction data can provide the experimental team with information about phases and proportions of metallic iron, oxides and hydroxide.

Reliable bulk elemental composition from PGAA or in-beam NAA can also be used on a routine basis to keep the activation risk of subsequent experiments under control (Kardjilov and Festa, 2017). For instance, the activity of 1 gram of $\mathrm{Cu}, \mathrm{Au}, \mathrm{Sb}$ or $\mathrm{Mn}$ irradiated for 3 hours in a beam of $10^{8} \mathrm{~cm}^{-2} \mathrm{~s}^{-1}$ thermal-equivalent slow-neutron flux (typical for PGAA) decays below the legal clearance limit within 24 hours. However, if the same material would be exposed to neutrons at a beamline with a significant epithermal component (e.g. 
Journal of Archaeological Science: Reports 20 (2018) 476-482 DOI:

10.1016/j.jasrep.2018.06.001

at RAD station) for 10 hours during a full tomography, the sample would remain active for two weeks due to Sb-122 and Au-198 isotopes (with half-lives of 2.7 days and significant resonance integrals). This has to be considered when planning the experimental work, as the precious objects can be borrowed from museums only for a limited time and they have to be declared inactive by or shortly after the end of the user's stay at the neutron center.

When applying different neutron instruments at different beamlines, or even at separate neutron centers, to the same $\mathrm{CH}$ object, the sampling volumes are not necessarily geometrically coincident and the penetration depths of the various radiations might differ (fast/thermal/cold/monochromatic neutrons, X-rays, charged particles), making inexact the merging of the available data. So there is a clear advantage to integrate multiple functionalities into a single instrument and analyze the object in several ways at once at the same beamline, in the same position, but with multiple means of detection. This paper presents the recent efforts to integrate the non-destructive, position sensitive elemental analysis (prompt gamma activation imaging, PGAI) with neutron imaging (radiography, NR or tomography, NT) (Belgya et al., 2008b, 2008a) at the NIPS-NORMA station (Z. Kis et al., 2015) of the BNC.

\section{Experimental}

The Budapest PGAA lab has 20 years of experience with analysis of various $\mathrm{CH}$ objects. Most samples with masses of a few grams and size of a few $\mathrm{cm}$ could fit well into our sample chamber, and, thanks to its modular structure, it can be partially taken apart to accommodate objects up to $50 \mathrm{~cm}$ in diameter. The extension of this well-established technique towards non-homogeneous samples was facilitated by making simultaneous use of a well-shielded gamma spectrometer, a neutron imaging camera placed downstream and a computer-controlled sample stage, all aligned around the isocentre (the geometrical intersection of the beam axis, the perpendicularly placed gamma-detector's symmetry axis and the vertical axis of the rotation stage of the sample positioner). PGAI-NT is therefore a combination of neutron imaging and element analysis, where the image is used i) as a visual feedback for sample positioning, ii) as a link between the structure and the local 
Journal of Archaeological Science: Reports 20 (2018) 476-482 DOI:

10.1016/j.jasrep.2018.06.001

composition, as well as iii) for correction for large-sample effects in non-destructive elemental analysis of non-homogeneous objects.

It is often more time-effective to avoid the point-wise scan of the entire object (Belgya et al., 2008b) with a few mm-resolution and to probe selectively only certain well-defined parts, e.g. regions of interest in the 3D space. This approach is called Radiography/Tomography-driven PGAI. If a real object is made of only a few distinct homogeneous parts (e.g. a restoration patch on a restored object), then localized promptgamma measurements made only at a few points could already be conclusive.

NIPS-NORMA (Z. Kis et al., 2015), the completely redesigned successor of the Ancient Charm PGAI-NT pilot setup (Szentmiklósi et al., 2009), was commissioned in 2012 to become the first permanent and routinely operating PGAI-NT facility in the world. The major technical features of the NIPS-NORMA station have been published (Z. Kis et al., 2015; Szentmiklósi et al., 2013); here only the most important facts are summarized. The samples can be accommodated in a sample chamber with dimensions of $200 \times 200 \times 200$ $\mathrm{mm}^{3}$, and irradiated by cold neutrons (flux: $2.7 \times 10^{7} \mathrm{~cm}^{-2} \mathrm{~s}^{-1}$, beam cross-section up to $43 \times 43 \mathrm{~mm}^{2}$, beam divergence (L/D ratio): $233-1833$ ). The images are taken with an Andor iKon-M camera with 16 bit bin depth and typical spatial resolution of $230 \mu \mathrm{m}$. The prompt-gamma radiation is detected with a $23 \%$-efficient, Compton suppressed high-purity germanium detector system placed inside 100-150 mm thick lead gamma-ray shielding. A neutron slit can shape the impinging beam to any rectangular form.

The projections are flat-field and dark-image corrected and reconstructed with the OCTOPUS 8.9 software (Cnudde and Vlassenbroeck, 2017). Afterwards, the 3D rendering and visualization is performed using VG Studio MAX 3.1 (Volume Graphics, 2017). The gamma spectra are evaluated with Hypermet-PC (Fazekas et al., 1996) or with PeakFit (Szentmiklósi, 2017) if batch processing is required, and the elemental concentrations are calculated with the Excel macro ProSpeRo (Révay, 2009). 
Journal of Archaeological Science: Reports 20 (2018) 476-482 DOI:

10.1016/j.jasrep.2018.06.001

\section{Results and discussion}

\subsection{Analysis of archaeological iron}

In the very first cultural-heritage-related study of the newly constructed NIPS-NORMA station the earliest known iron artefacts, three small beads dated to $3200 \mathrm{BC}$, from Gerzeh, Egypt, presently owned by the University College of London, Petrie Museum of Egyptology (Inv. No: UC10738, UC10739 and UC10740), were investigated. We have demonstrated with the detection of specific element signatures that these beads were made of meteoritic iron, and shaped by hammering the metal into thin sheets before rolling them into tubes (Rehren et al., 2013). The study revealed the advantages of neutron and complementary X-ray methods to determine the nature of the material even after complete corrosion of the iron metal. Our conclusions were later confirmed by Johnson et al. (Johnson et al., 2013) using X-ray based techniques only.

A similar methodology was used in another study, where it was possible to establish a correlation between the longitudinal chlorine profile and the degree of corrosion in archaeological iron nails (Watkinson et al., 2014). After excavation, oxidation forms ferrous chloride and hydroxide, which cause cracking, fragmentation and break-up of the objects. The thick corrosion layer and the intact iron core were easy to separate in the 3D neutron images, much more recognizable than in X-ray radiograms, allowing us to correlate the corroded layer's thickness with the higher local chlorine content. This was a clear indication about the driving force of the corrosion. So the experiment confirmed that the PGAI-NT technique provides comparable results to the previously used chlorineanalysis approach by ion-selective electrodes, but in a non-destructive way.

\subsection{Analysis of sealed pottery}

Neutron techniques have significant advantages in the analysis of archaeological materials, including greater penetration depth and lower elemental detection limits, over other modalities, not only for heavy-metals, but already for lower-Z materials, found e.g. in ceramics and organics. A good example is an Eighteenth Dynasty (XV $\left.{ }^{\text {th }} \mathrm{c} . \mathrm{BC}\right)$ Egyptian sealed pottery vessel stored at the Museum of Aquitaine (Bordeaux, France, inventory 
Journal of Archaeological Science: Reports 20 (2018) 476-482 DOI:

10.1016/j.jasrep.2018.06.001

number 8608) that has been investigated using Terahertz-frequency (THz) electromagnetic radiation, X-rays and neutrons. The internal mobile content of the pottery was identified using neutrons as dried organic material, whereas the bottle sealing was found to contain an external red clay layer on the top of an internal bunch of linen (Abraham et al., 2014). The other two modalities suffered either from missing contrast, or from missing resolution; clearly the neutron imaging provided the most useful visualization.

\subsection{Analysis of archaeological bronzes}

\subsubsection{The South-Levantine bronze sculpture: The Naked Goddess}

The Collection of Egyptian Antiquities at the Museum of Fine Art in Budapest possesses a statuette composed of a naked goddess with palm trees and sitting monkeys on both sides (Inv. No. 2007.2-E), with suspected South-Levantine origin. Based on the visual appearance and religious iconography of the object it was dated to the Late Bronze Age I (1550-1400 BC). It was suspected that its broken palm stubs are filled with an ironcontaining material, possible with meteoritic origin, to emphasize its celestial nature. The goals of the study were to determine the elemental composition, to assess whether the different parts share the same composition (i.e. one-step manufacturing) or not, and to identify the related parts within the composition. The object was analyzed with PGAI for bulk composition (Maróti et al., 2017), neutron radiography and neutron tomography for its structure and spatial inhomogeneity (Maróti et al., 2017) and with hhXRF (Innov-X Delta Premium handheld XRF spectrometer (Olympus, 2011), using its Alloy Plus mode) for the first-glance, rapid material identification needed to optimize the neutron experiment and determine the surface composition. Literature suggested that a compositional difference between surface and bulk is relevant for the production technique of the object (Szabó, 2002, 1998). Measurement spots are depicted in Fig 1, on the left for handheld X-

ray Fluorescence Spectrometry, and at the right for imaging-driven PGAI. The corresponding concentration data are given in Table 1. 


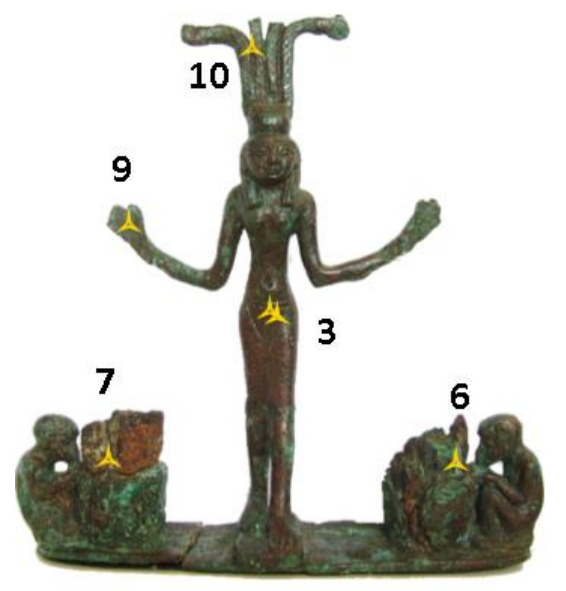

Handheld XRF measurement spots

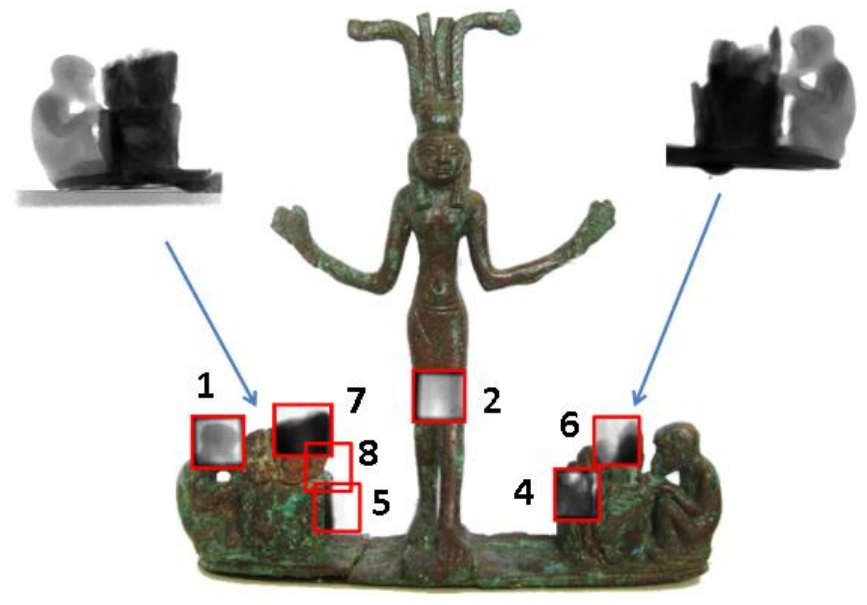

PGAI-NT measurement spots

Figure 1 The analyzed spots with hhXRF (left) and radiography-driven PGAI (right). See Table 1 for the compositions of the indicated measurement positions

\begin{tabular}{c|c|cc} 
Analyzed region & $\begin{array}{c}\text { ID Number in } \\
\text { Figure } \mathbf{1 .}\end{array}$ & $\begin{array}{c}\text { Sn/Cu mass } \\
\text { ratio PGAI }\end{array}$ & $\begin{array}{c}\text { Sn/Cu mass } \\
\text { ratio hhXRF }\end{array}$ \\
\hline Left Monkey head & 1 & $\mathbf{0 . 1 5 7} \pm \mathbf{0 . 0 0 5}$ & - \\
Goddess leg & 2 & $\mathbf{0 . 1 6 4} \pm \mathbf{0 . 0 0 4}$ & - \\
Goddess belly & 3 & - & $0.209 \pm 0.001$ \\
Right side bottom palm stub & 4 & $\mathbf{0 . 1 6 5} \pm \mathbf{0 . 0 0 4}$ & - \\
Left side bottom palm stub & 5 & $\mathbf{0 . 1 6} \pm \mathbf{0 . 0 1}$ & - \\
Right side upper palm stub & 6 & $0.131 \pm 0.005$ & $0.152 \pm 0.001$ \\
Left side upper palm stub & 7 & $<\mathrm{LOD}$ & $0.150 \pm 0.001$ \\
Left side palm stub (middle) & 8 & $0.227 \pm 0.009$ & - \\
Goddess right hand & 9 & - & $0.175 \pm 0.001$ \\
Goddess crown & 10 & - & $0.201 \pm 0.001$
\end{tabular}

Table 1. $\mathrm{Sn} / \mathrm{Cu}$ mass ratios at several spots of the sculpture. The data in bold are in agreement within the standard deviation, proving the common raw material of these parts and proving the authenticity of the broken fragment, consisting of the left-hand monkey and the palm stub.

Using prompt-gamma activation analysis, the base alloy of the sculpture group was identified as tin-bronze with 86 weight percent (wt\%) $\mathrm{Cu}$ and $14 \mathrm{wt} \% \mathrm{Sn}$ (corresponding to $\sim 0.163 \mathrm{Sn} / \mathrm{Cu}$ mass ratio). Based on the analyses carried out at different parts of the sculpture group it was concluded that the goddess and the monkey figurines, the base and 
Journal of Archaeological Science: Reports 20 (2018) 476-482 DOI:

10.1016/j.jasrep.2018.06.001

the lower parts of the palm stubs are all made of the above mentioned material. The handheld XRF data scattered much beyond their uncertainties. It is very sensitive to the patina and other surface effects, since it has only a limited sampling spot size and penetration depth. This case study demonstrated that neutron-based elemental composition data are more robust and more representative than the more commonly used hhXRF results, unless the surface is properly cleaned before the analysis. It was also proven that the common raw material composition of the goddess and the monkey-parts is a strong evidence for the authenticity of the broken fragment.

Based on the synthesis of the elemental composition data and 3D neutron attenuation data, one could interpret the complex layout of the object with some confidence. The lower part of the palm stub is hollow, while the monkey figures and the base are solid castings (shown with yellow in the third panel of Figure 2). The palm stub consists of stacked pieces of corroded iron (shown with red in the third panel of Figure 2) with void volumes and a filling material inside. The comparison of surface (hhXRF) and bulk (PGAI) composition data at the upper palm stub indicated an excess of $\mathrm{Mn}, \mathrm{Pb}$ and $\mathrm{S}$ in the bulk compared to the surface (see Table 2). This, in combination with the visual structural information led to the conclusion that they are components of the filling material.

\begin{tabular}{c|ccc} 
Left side upper palm stub & PGAI & hhXRF & PGAI/hhXRF \\
\hline $\mathrm{Mn} / \mathrm{Fe}$ & $0.174 \pm 0.007$ & $0.0051 \pm 0.0003$ & 34 \\
$\mathrm{~Pb} / \mathrm{Fe}$ & $0.89 \pm 0.08$ & $0.017 \pm 0.001$ & 5 \\
$\mathrm{~S} / \mathrm{Fe}$ & $0.43 \pm 0.01$ & $0.050 \pm 0.002$ & 10
\end{tabular}

Table 2. Comparison of the bulk (PGAI) and surface (hhXRF) mass ratios for elements more abundant in the filling material

The tomography data was visualized and segmented with the volume rendering software to differentiate between adjacent materials. Finally, the volumetric tomography data was converted to a surface mesh that approximates the surfaces with a set of tiny triangles ( $\mathrm{T}$ Biró et al., 2014). This STL file can be loaded to a modeling, animation and rendering software package to create a textured, realistic-looking digital representation or to CAD software to obtain properties like linear extent, volume, surface area or center of gravity. It can also be excellent input for a "virtual exhibition". 
Journal of Archaeological Science: Reports 20 (2018) 476-482 DOI:

10.1016/j.jasrep.2018.06.001

Moreover, with a Stratasys Mojo type 3D printer ("Stratasys Mojo 3D printer," 2017) we were able to create a plastic replica of the object. This emerging technology, heavily used in rapid industrial prototyping, has the potential to:

- offer a tangible presentation about the anatomy of even a fragile object to a broad audience (e.g. students);

- allow designing custom sample supports for each valuable $\mathrm{CH}$ object at a largescale neutron facility.

- fabricate templates in order to replicate objects (e.g. museum souvenirs)
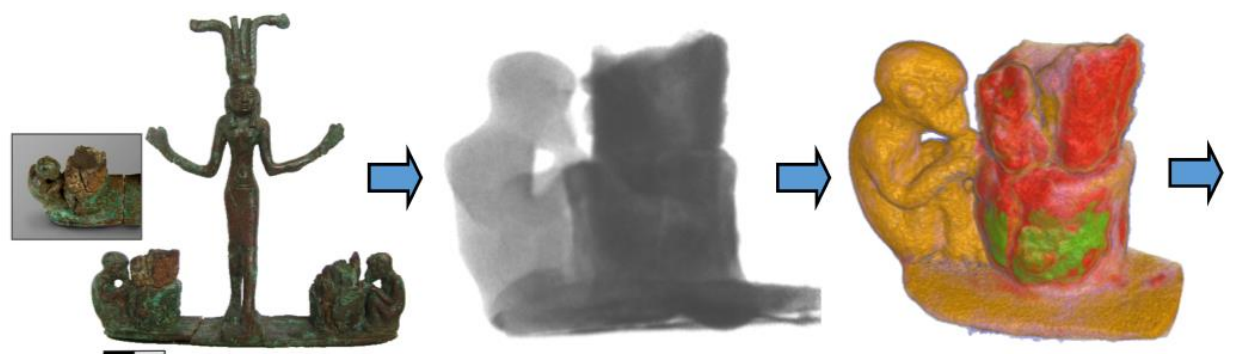

1. Art object

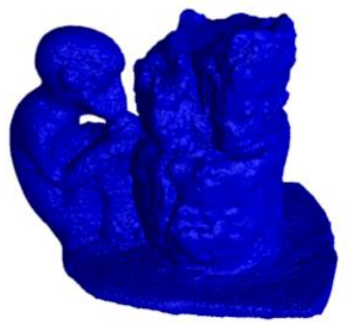

4. Point cloud \& surface mesh
2. Radiogram 3. 3D reconstruction \& segmentation
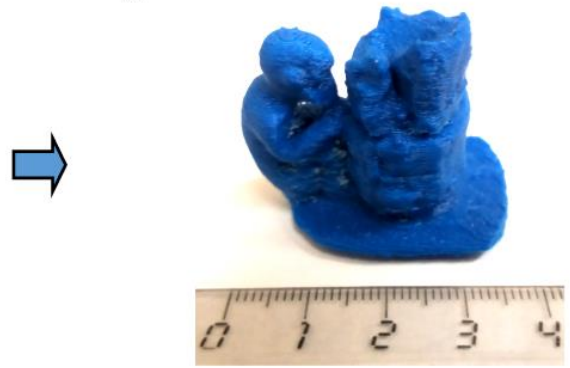

5. 3D-printed replica

Figure 2. The workflow of the data processing

\subsubsection{Ottoman bronze weights}

In most cases, the inner structure and elemental composition of Ottoman balance weights from the $16^{\text {th }}-19^{\text {th }}$ century are poorly described in the literature. Some pieces were dated to the Roman age and kept in the Roman collection of the Hungarian National Museum, based on their visual appearance. Therefore, the objects that can confidently be dated to the Ottoman (Turkish Empire) occupancy of Hungary, based on the archaeological context 
Journal of Archaeological Science: Reports 20 (2018) 476-482 DOI:

10.1016/j.jasrep.2018.06.001

and/or excavation site, can have special significance in re-classification of similar objects.

To contribute to this effort of re-classification, we studied a well-documented object from the Turkish collection of the Hungarian National Museum, a balance weight from Ócsa (catalog number: 92.57.2.B). It is a pear-shaped object dated to the $16^{\text {th }}$ century which has a mass of $165 \mathrm{~g}$, equivalent to 50 dirhem (dirhem is a Turkish weight (3.2 g) and also currency unit). It was presumed that the object has a lead filling inside a bronze mantle (Fehér, 1993).

Again, the comprehensive analysis procedure started with a hhXRF analysis carried out previously in the Museum's vault (Table 3a).

\begin{tabular}{c|cccccccc} 
Position & \multicolumn{3}{|c}{$\mathbf{1}$} & \multicolumn{2}{c}{$\mathbf{2}$} & \multicolumn{2}{c}{$\mathbf{3}$} & \multicolumn{2}{c}{$\mathbf{4}$} \\
\hline Element & wt\% & \pm & wt\% & \pm & wt\% & \pm & wt\% & \pm \\
\hline Cu & 98.6 & 0.1 & 79.2 & 0.1 & 89.7 & 0.2 & 69.42 & 0.1 \\
Sn & 0.68 & 0.01 & 4.15 & 0.04 & 5.09 & 0.07 & 3.45 & 0.04 \\
Pb & 0.55 & 0.01 & 14.9 & 0.07 & 3.74 & 0.06 & 22.0 & 0.1 \\
Sb & 0.07 & 0.01 & 0.79 & 0.02 & 0.38 & 0.04 & 0.70 & 0.02 \\
Bi & $<$ LOD & & 0.29 & 0.02 & 0.21 & 0.02 & 0.33 & 0.02 \\
Fe & 0.10 & 0.007 & 0.57 & 0.01 & 0.61 & 0.02 & 3.73 & 0.03 \\
Mn & LOD & & 0.02 & 0.01 & 0.19 & 0.01 & $<$ LOD &
\end{tabular}

Table 3a. Handheld XRF results in mass percent unit. Top left panel of Figure 3 illustrates the positions of the measurement areas with red circles (LOD: limit of detection)

These results, from several points on the surface, were not conclusive for the bronze alloy composition, likely because of previous restoration work and surface treatment processes, so a non-destructive bulk analytical method, the imaging-driven PGAI was used. With this approach, we found $84 \mathrm{wt} \% \mathrm{Cu}, 3.8 \mathrm{wt} \% \mathrm{Sn}$ and $10 \mathrm{wt} \% \mathrm{~Pb}$ in the hook, and $32 \mathrm{wt} \% \mathrm{Cu}$, $1.5 \mathrm{wt} \% \mathrm{Sn}$ and $59 \mathrm{wt} \% \mathrm{~Pb}$ in a volume containing both the mantle and the filling material. If these are recalculated in mass fraction units relative to $\mathrm{Cu}$, elements that are part of the base alloy ( $\mathrm{Sn}, \mathrm{Ag}, \mathrm{Ni})$ agree well within statistics at the two sampling volumes. However, the $\mathrm{Fe}, \mathrm{Mn}$, and $\mathrm{Pb}$ mass fractions differ, far beyond the statistical uncertainty, between the mantle and the top part of the hook, showing that these elements are much more abundant in the filling material than in the mantle, assuming the same casted alloy for the hook and the mantle (Table 3b). 
Journal of Archaeological Science: Reports 20 (2018) 476-482 DOI:

10.1016/j.jasrep.2018.06.001

\begin{tabular}{|c|c|c|c|c|c|c|c|c|}
\hline \multirow[t]{2}{*}{ Element } & \multicolumn{2}{|c|}{$\begin{array}{c}\text { Hook (top } \\
\text { part) }\end{array}$} & \multicolumn{2}{|c|}{$\begin{array}{c}\text { Mantle }+ \text { Filling } \\
\text { material }\end{array}$} & \multicolumn{2}{|c|}{ Hook (top part) } & \multicolumn{2}{|c|}{$\begin{array}{c}\text { Mantle }+ \text { Filling } \\
\text { material }\end{array}$} \\
\hline & wt $\%$ & \pm & wt $\%$ & \pm & $\begin{array}{l}\text { Element } / \mathrm{Cu} \\
\text { mass fraction }\end{array}$ & \pm & $\begin{array}{c}\text { Element/Cu } \\
\text { mass } \\
\text { fraction }\end{array}$ & \pm \\
\hline $\mathrm{Cu}$ & 84 & 1.1 & 32 & 0.9 & & & & \\
\hline $\mathrm{Sn}$ & 3.8 & 0.3 & 1.5 & 0.1 & 0.045 & 0.004 & 0.047 & 0.003 \\
\hline $\mathrm{Pb}$ & 10 & 1 & 59 & 1 & 0.12 & 0.01 & 1.84 & 0.06 \\
\hline $\mathrm{Ag}$ & 0.17 & 0.01 & 0.068 & 0.005 & 0.002 & 0.0002 & 0.0021 & 0.0002 \\
\hline $\mathrm{Fe}$ & 0.76 & 0.05 & 6.7 & 0.2 & 0.009 & 0.001 & 0.209 & 0.009 \\
\hline $\mathrm{Ni}$ & 0.21 & 0.01 & 0.071 & 0.002 & 0.0025 & 0.0001 & 0.0022 & 0.0002 \\
\hline $\mathrm{Mn}$ & 0.31 & 0.03 & 0.77 & 0.2 & 0.0037 & 0.0003 & 0.024 & 0.001 \\
\hline
\end{tabular}

Table $3 b$. PGAI results in mass percent units and elemental mass fractions relative to $\mathrm{Cu}$.

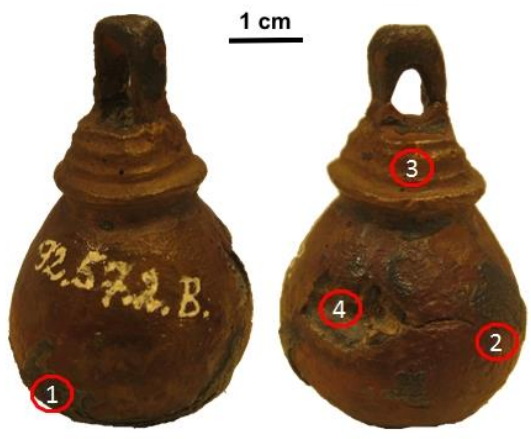

1. handheld XRF measurements

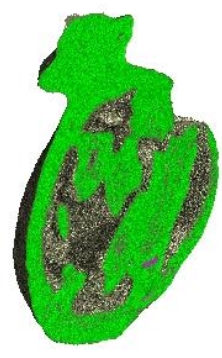

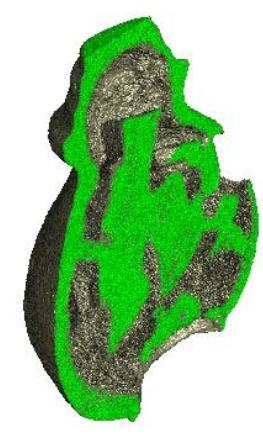
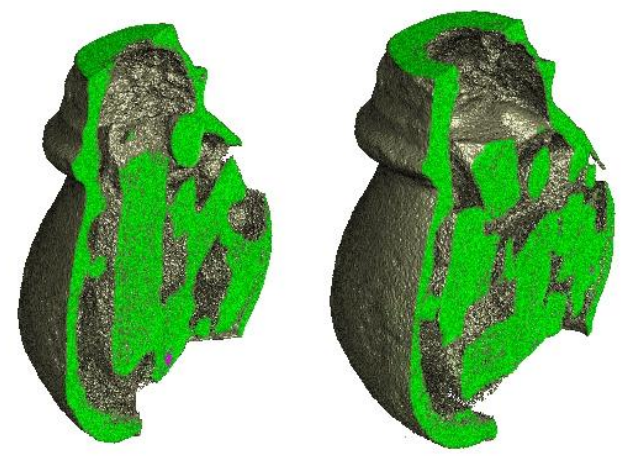

3. neutron tomography

Figure 3. The photo (1), cold-neutron radiograms (2) and tomographic cuts (3) of the bronze weight. Red circles in panel 1: hhXRF measurement spots; yellow symbols in panel 2: PGAI measurement spots 
Journal of Archaeological Science: Reports 20 (2018) 476-482 DOI:

10.1016/j.jasrep.2018.06.001

\subsubsection{Rivet of a bronze dagger}

A bronze dagger (Inventory number 56.15.1568) and three other fragments from the Füzesabony-Öregdomb settlement, dated to the $16^{\text {th }}-15^{\text {th }}$ century BC, i.e. Early or Middle Bronze Age were analyzed, out of the few available conical headed pins, daggers, flanged axes, socketed spearheads and seven moulds that indicate a local bronze metallurgy (Szathmári, 2003). The analyzed rivets were used to mount the handle of the dagger.

From the elemental analysis results, we identified a clear difference between surface and bulk compositions. The surface-related hhXRF data showed an alloy of about $70 \mathrm{wt} \% \mathrm{Cu}$ and a variable Sn content (0.7-8 wt\%), whereas bulk results measured by PGAI were 86 wt $\% \mathrm{Cu}$ and $5.9 \mathrm{wt} \% \mathrm{Sn}$. These two major components do not sum up to $100 \%$. Some lighter elements, e.g. Si, S and Fe were also present at $1 \%$ levels. The differences in elemental compositions found on the surface and in the bulk are attributed to soil contamination, or to near-surface corrosion, as well as to the concentration gradients caused by the fabrication.

The horizontal and vertical cuts of the neutron tomogram clearly depicted a core (bluegreen) part and a surrounding, homogeneous base alloy (orange), as visualized in Fig 4.

We came to the conclusion that the rivet \#2, highlighted with a red frame in Figure 4, is in fact a broken piece of the dagger that came off together with the rivet. The rivet was created from a wire with a different tin-content, and was hammered from both sides to fix the dagger to the organic handle (wood or antler). Even the thickness of the missing handle can be assessed from the length of the rivet. The tomographic images clearly prove a compaction of the two ends of the rivet (blue regions). This is perfectly supported by the conclusions made in (Szabó, 2013) (pages 29 and 159), but there the destructive thin section analysis was used. The compaction induced a long-term corrosion due to the deformation of the lattice structure, resulting in the corroded middle (light green) regions.

The experiment finally allowed us to better understand the layout of the dagger and how its handle was attached to the blade. 
Journal of Archaeological Science: Reports 20 (2018) 476-482 DOI:

10.1016/j.jasrep.2018.06.001

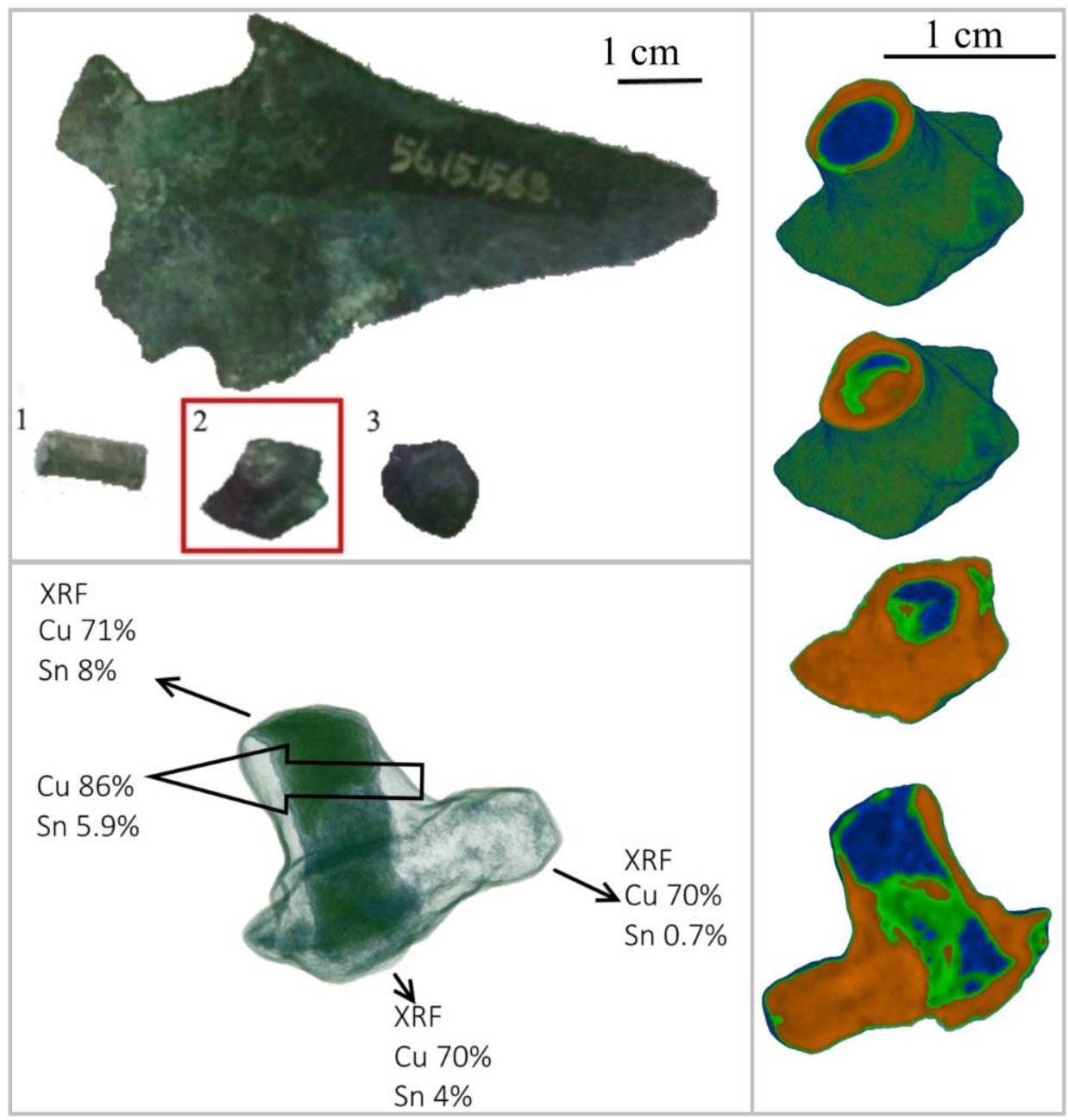

Figure 4. The structure and composition of the rivet \#2 shown within the red frame.

\section{Conclusions}

We have demonstrated that neutron-based techniques, in particular elemental analysis (PGAA, PGAI) and imaging, are potent methods to characterize cultural heritage objects in a non-destructive way, and adequate to a large extent to avoid the issues related to sampling, mechanical thin sectioning, and sampling-volume representativity. It was also 
Journal of Archaeological Science: Reports 20 (2018) 476-482 DOI:

10.1016/j.jasrep.2018.06.001

pointed out that the integrated use of multiple techniques has a synergetic effect and these combined results can be more easily interpreted than separate data from independent experiments.

If the surface composition is different from the bulk due to patina or oxide layers, or due to technical fabrication reasons, the composition of the base alloy can be more confidently determined from the bulk composition results by PGAI than using the surface sampling by hhXRF, whereas the differences found between surface and bulk compositions are indicative in some cases of the structure or the fabrication technology.

\section{Acknowledgements}

L.Sz. gratefully acknowledges the financial support of the Bolyai János Research Fellowship of the Hungarian Academy of Sciences. This work was part of the Project No. 124068 that has been implemented with the support provided from the National Research, Development and Innovation Fund of Hungary, financed under the K_17 funding scheme. Some of the experiments presented here were carried out with financial contributions from the CHARISMA (EC FP7 Grant No: 228330) and IPERION CH (EC H2020 Grant No: 654028) projects.

We thank the Egyptologist experts from the Museum of Fine Arts in Budapest, in particular Éva Liptay, for providing the sculpture group for analysis and Péter Gaboda for the useful discussions concerning the origin of the object. We thank Ibolya Gerelyes and Gábor Tomka of the Hungarian National Museum for providing the Turkish balance samples for analysis. We also thank our collaborators from the Momentum Mobility Research Group, Hungarian Academy of Sciences, Viktória Kiss (Institute of Archaeology, Research Centre for the Humanities, Hungarian Academy of Sciences), Ildikó Szathmári (Hungarian National Museum), and Géza Szabó (Wosinsky Mór Museum, Szekszárd) for data concerning archaeological material and Bronze Age production techniques. We gratefully acknowledge the help of József Janik in 3D printing and Jesse L. Weil for his valuable comments to improve the manuscript. 
Journal of Archaeological Science: Reports 20 (2018) 476-482 DOI:

10.1016/j.jasrep.2018.06.001

\section{References}

Abraham, E., Bessou, M., Ziéglé, A., Hervé, M.-C., Szentmiklósi, L., Kasztovszky, Z.S., Kis, Z., Menu, M., 2014. Terahertz, X-ray and neutron computed tomography of an Eighteenth Dynasty Egyptian sealed pottery. Appl. Phys. A Mater. Sci. Process. 117. https://doi.org/10.1007/s00339-014-8779-3

Belgya, T., Kis, Z., Szentmiklósi, L., Kasztovszky, Z., Festa, G., Andreanelli, L., De Pascale, M.P., Pietropaolo, A., Kudejova, P., Schulze, R., Materna, T., 2008a. A new PGAI-NT setup at the NIPS facility of the Budapest Research Reactor. J. Radioanal. Nucl. Chem. 278, 713-718. https://doi.org/10.1007/s10967-008-1510-0

Belgya, T., Kis, Z., Szentmiklósi, L., Kasztovszky, Z., Kudejova, P., Schulze, R., Materna, T., Festa, G., Caroppi, P.A., 2008b. First elemental imaging experiments on a combined PGAI and NT setup at the Budapest Research Reactor. J. Radioanal. Nucl. Chem. 278. https://doi.org/10.1007/s10967-008-1605-7

Cnudde, V., Vlassenbroeck, J., 2017. Octopus Neutron Tomography reconstruction software, https://octopusimaging.eu/

Edge, D., Williams, A., Kasztovszky, Z., Kis, Z., Kovács, I., Rosta, L., Szőkefalvi-Nagy, Z., Káli, G., 2015. Nondestructive Methods of Analysis Applied to Oriental Swords. Gladius 139-158.

Fazekas, B., Belgya, T., Dabolczi, L., Molnár, G., Simonits, A., 1996. HYPERMET-PC: Program for automatic analysis of complex gamma- ray spectra. J. Trace Microprobe Tech. 14, 167-172.

Fehér, G., 1993. Oszmán-török mérlegsúlyok, in: Fodor, I. (Ed.), Communicationes Archaeologicae Hungariae. pp. 231-247.

Giorini, G., Kamermans, H., Cattaneo, R., Perelli Cippoi, E., Pietropaolo, A., Tardocchi, M., Andreani, C., Adembri, Arancio, M.L., Caroppi, B., de Pascale, M., Festa, G., Malfitana, D., Senesi, R., Giusti, A.M., Recchia, A.P., Porcinai, S., Biro, K.T., Duzs, K., Hajnal, Z., Belgya, T., Kasztovszky, Z., Kis, Z., Szentmiklosi, L., Kirfel, A., Jolie, J., Schulze, R., Kudejova, P., Schillebeeckx, P., Borella, A., Materna, T., Fontijn, D., Amkreutz, L., Scholten, S., van Eijk, C.W.E., Bom, V.R., Clarijs, M.C., Moxon, M.C., Postma, H., Godfrey, E., Kockelmann, W., Radaelli, P., Rhodes, N.J., Schooneveld, E.M., Visser, D., 2009. Neutron-based Analysis for Cultural Heritage Research.Results of the Ancient Charm project, in: 14th International Congress „Cultural Heritage and New Technologies“.

Gliozzo, E., Kockelmann, W.A., Artioli, G., 2017. Neutron diffraction of Cu-Zn-Sn ternary alloys: non-invasive assessment of the compositions of historical bronze/brass copper ternary alloys. J. Appl. Crystallogr. 50, 49-60. https://doi.org/10.1107/S1600576716017805 
Journal of Archaeological Science: Reports 20 (2018) 476-482 DOI:

10.1016/j.jasrep.2018.06.001

Johnson, D., Tyldesley, J., Lowe, T., Withers, P.J., Grady, M.M., 2013. Analysis of a prehistoric Egyptian iron bead with implications for the use and perception of meteorite iron in ancient Egypt. Meteorit. Planet. Sci. 48, 997-1006. https://doi.org/10.1111/maps.12120

Káli, G., Sánta, Z., Bleif, H.J., Mezei, F., Rosta, L., Szalók, M., 2007. Installation of the high resolution TOF diffractometer at the Budapest Research Reactor, in: Zeitschrift Fur Kristallographie, Supplement. pp. 165-170.

Kardjilov, N., Festa, G., 2017. Neutron Methods for Archaeology and Cultural Heritage. Neutron Scatt. Appl. Tech. https://doi.org/10.1007/978-3-319-33163-8

Kasztovszky, Z., Káli, G., Kis, Z., Kovács, I., Len, A., Maróti, B., Pánczél-Bajnok, K., Rosta, L., Szőkefalvi-Nagy, Z., 2016. Applications of neutron-based and ion beam methods in Cultural Heritage research at the Budapest Neutron Centre, Techné. La Sci. au Serv. l'historie l'art des civilisations 43, 70-74.

Kis, Z., Szentmiklósi, L., Belgya, T., 2015. NIPS-NORMA station - A combined facility for neutron-based nondestructive element analysis and imaging at the Budapest Neutron Centre. Nucl. Instruments Methods Phys. Res. Sect. A Accel. Spectrometers, Detect. Assoc. Equip. 779. https://doi.org/10.1016/j.nima.2015.01.047

Kis, Z., Szentmiklósi, L., Belgya, T., Balaskó, M., Horváth, L.Z., Maróti, B., 2015. Neutron based imaging and element-mapping at the Budapest Neutron Centre, 10 World Conference on Neutron Radiography 5-10 October 2014. Phys. Procedia 69, $40-47$.

Kiss, V., Fischl, K.P., Horvath, E., Kali, G., Kasztovszky, Z., Kis, Z., Maroti, B., Szabo, G., 2015. Non-destructive analyses of bronze artefacts from Bronze Age Hungary using neutron-based methods. J. Anal. At. Spectrom. 30, 685-693. https://doi.org/10.1039/c4ja00377b

Kudejova, P., Révay, Z., Kleszcz, K., Genreith, C., Rossbach, M., 2015. High-flux PGAA for milligram-weight samples. EPJ Web Conf. 93, 08001-08002. https://doi.org/10.1051/epjconf/20159308002

Lehmann, E., 2017. Neutron Imaging Facilities in a Global Context. J. Imaging 3, 52. https://doi.org/10.3390/jimaging3040052

Lehmann, E., Mannes, D., Kaestner, A., Grünzweig, C., 2017. Recent Applications of Neutron Imaging Methods. Phys. Procedia 88, 5-12. https://doi.org/10.1016/j.phpro.2017.06.055

Mackey, E.A., Anderson, D.L., Chen, H., Downing, R.G., Greenberg, R.R., Lamaze, G.P., Lindstrom, R.M., Mildner, D.F.R., Paul, R.L., 1996. Use of neutron beams for chemical analysis at NIST. J. Radioanal. Nucl. Chem. 203, 413-427. 
Journal of Archaeological Science: Reports 20 (2018) 476-482 DOI:

10.1016/j.jasrep.2018.06.001

Maróti, B., Kis, Z., Szentmiklósi, L., Horváth, E., Káli, G., Belgya, T., 2017. Characterization of a South-Levantine bronze sculpture using position-sensitive prompt gamma activation analysis and neutron imaging. J. Radioanal. Nucl. Chem. 312. https://doi.org/10.1007/s10967-017-5219-9

Molnár, G.L., 2004. Handbook of Prompt Gamma Activation Analysis with Neutron Beams.

Olympus, 2011. Innov-X DELTA Handheld XRF Analyzer https://www.olympusims.com/hu/xrf-xrd/xrf-handheld/

Rehren, T., Belgya, T., Jambon, A., Káli, G., Kasztovszky, Z., Kis, Z., Kovács, I., Maróti, B., Martinón-Torres, M., Miniaci, G., Pigott, V.C., Radivojević, M., Rosta, L., Szentmiklósi, L., Szőkefalvi-Nagy, Z., 2013. 5,000 years old Egyptian iron beads made from hammered meteoritic iron. J. Archaeol. Sci. 40, 4785-4792. https://doi.org/10.1016/j.jas.2013.06.002

Révay, Z., 2009. Determining Elemental Composition Using Prompt-gamma Activation Analysis. Anal. Chem. 81, 6851-6859.

Schillinger, B., Fedrigo, A., Grazzi, F., Kullmer, O., Laaß, M., M. Makowska, I. Werneburg, C. Zanolli, 2018. Neutron Imaging in Cultural Heritage Research at the FRM II Reactor of the Heinz Maier-Leibnitz Center. J. Imaging 4, 22. https://doi.org/10.3390/jimaging4010022

Schulze, R., Szentmiklósi, L., Kis, Z. and the Ancient Charm Collaboration, 2010. The Ancient Charm Project: New neutron based imaging methods for cultural heritage studies. Archeol. E Calc. 21, 281-299.

Sidot, E., Kahn-Harari, A., Cesari, E., Robbiola, L., 2005. The lattice parameter of $\alpha$ bronzes as a function of solute content: Application to archaeological materials. Mater. Sci. Eng. A 393, 147-156. https://doi.org/10.1016/j.msea.2004.10.001

Stratasys Mojo 3D printer, http://www.stratasys.com/3d-printers/mojo

Szabó, G., 2013. A dunántúli urnamezős kultúra fémmüvessége az archaeometallurgiai vizsgálatok tükrében (The metallurgy of the Transdanubien urnfield culture in light of archaeometallurgical investigations). PTE-BTK-TTI, Ókortörténeti Tanszék, Pécs. ISBN 978-963-642-506-7

Szabó, G., 2002. Archaeometallurgical investigations of the LBA bronze objects in the Carpathian Basin, in: Jerem, E., T. Biró, K. (Eds.), Archaeometry 98: Proceedings of the 31st Symposium. Archaeopress, Gordon House, Oxford, UK, Oxford, pp. 481490.

Szabó, G., 1998. Evaluation of Late Bronze Age Carpathian tinbronzes based on the alloying content, in: Költő, L., Bartosiewicz, L. (Eds.), Archaeometrical Research in Hungary II. Magyar Nemzeti Múzeum; Somogy-megyei Múzeumok Igazgatósága, 
Journal of Archaeological Science: Reports 20 (2018) 476-482 DOI:

10.1016/j.jasrep.2018.06.001

Budapest, pp. 159-173.

Szathmári, I., 2003. The florescence of the Middle Bronze Age in the Tisza Region: the Füzesabony Culture, in: Visy, Z. (Ed.), Hungarian Archaeology at the Turn of the Millennium. Department of Monuments of the Ministry of National Cultural Heritage, pp. 156-157.

Szentmiklósi, L., 2017. Fitting special peak shapes of prompt gamma spectra. J. Radioanal. Nucl. Chem. 1-8. https://doi.org/10.1007/s10967-017-5589-z

Szentmiklósi, L., Belgya, T., Révay, Z., Kis, Z., 2010. Upgrade of thePrompt-Gamma Activation Analysis (PGAA) and the Neutron InducedPrompt-gamma Spectroscopy (NIPS) facilities at the Budapest ResearchReactor. J. Radioanal. Nucl. Chem. 286, 501-505. https://doi.org/10.1007/s10967-010-0765-4

Szentmiklósi, L., Kasztovszky, Z., Belgya, T., Révay, Z., Kis, Z., Maróti, B., Gméling, K., Szilágyi, V., 2016. Fifteen years of success: user access programs at the Budapest prompt-gamma activation analysis laboratory. J. Radioanal. Nucl. Chem. 309, 71-77. https://doi.org/10.1007/s10967-016-4774-9

Szentmiklósi, L., Kis, Z., Belgya, T., Berlizov, A.N., 2013. On the design and installation of a Compton-suppressed HPGe spectrometer at the Budapest neutron-induced prompt gamma spectroscopy (NIPS) facility. J. Radioanal. Nucl. Chem. 298. https://doi.org/10.1007/s10967-013-2555-2

Szentmiklósi, L., Kis, Z., Belgya, T., Kasztovszky, Z., Kudejova, P., Materna, T., Schulze, R., and the Ancient Charm Collaboration, 2009. The new PGAI-NT setup and the first elemental imaging experiments at the Budapest Research Reactor. In Proc. 7th International Conference on Nuclear and Radiochemistry, CD-ROM

Szilágyi, V., Kis, Z., Szentmiklósi, L., 2016. Neutron imaging for archaeometry. Archeometriai Mühely XIII, 157-172.

T Biró, K., Szabó, L.M., Szentmiklósi, L., Korom, C., Salamon, I., 2014. 3D Visualisation and Multidisciplinary Analytical Techniques on Cultural Heritage Objects From the Collection of the Hungarian National Museum. Archeometriai Mühely XI, 243-250.

Vergard, L., 1921. Die Konstitution der Mischkristalle und die Raumfullung der Atome. Zeitschrift für Phys. 5, 17-26. https://doi.org/10.1007/BF00549722

Volume Graphics, 2017. VG Studio Max. http://www.volumegraphics.com

Watkinson, D., Rimmer, M., Kasztovszky, Z., Kis, Z., Maróti, B., Szentmiklósi, L., 2014. The Use of Neutron Analysis Techniques for Detecting The Concentration And Distribution of Chloride Ions in Archaeological Iron. Archaeometry 56, 841-859. https://doi.org/10.1111/arcm.12058 